\title{
Clinical features of oral lichen planus. A retrospective study of 65 cases
}

\author{
Eulàlia Torrente-Castells ${ }^{1}$, Rui Figueiredo ${ }^{2}$, Leonardo Berini-Aytés ${ }^{3}$, Cosme Gay-Escoda ${ }^{4}$
}

${ }^{1}$ DDS. Master degree program in Oral Surgery and Implantology. Barcelona University Dental School

${ }^{2}$ DDS. Master degree program in Oral Surgery and Implantology. Associate professor of Oral Surgery and Professor of the Master degree program of Oral Surgery and Implantology. University of Barcelona Dental School. Researcher of the IDIBELL institute ${ }^{3}$ MD, DDS, PhD. Professor of Oral and Maxillofacial Surgery. Subdirector of the Master degree program of Oral Surgery and Implantology. Researcher of the IDIBELL institute

${ }^{4} \mathrm{MD}$, DDS, PhD. Chairman of Oral and Maxillofacial Surgery. Director of the Master degree program of Oral Surgery and Implantology. University of Barcelona Dental School. Coordinating investigator of the IDIBELL Institute. Head of the Service of Maxillofacial Surgery, Teknon Medical Center. Barcelona, Spain

Correspondence:

Centro Médico Teknon

Instituto de investigación IDIBELL

C/Vilana 12

08022 - Barcelona (Spain)

cgay@ub.edu

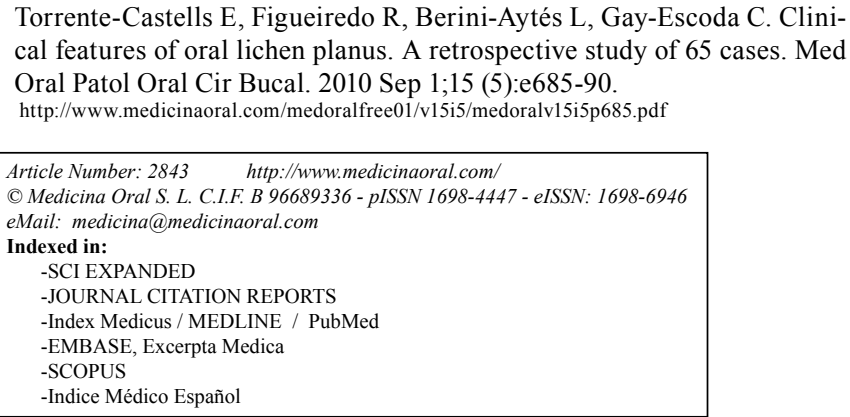

\begin{abstract}
Objectives: To describe the clinical features of patients diagnosed with oral lichen planus (OLP) and to establish the prevalence of its malignant transformation in our setting.

Study design: A retrospective study was made of 65 patients clinically and histologically diagnosed with OLP in the Service of Oral Surgery (Dental Clinic of the University of Barcelona, Spain) in the period 1990-2005. A descriptive and bivariate statistical analysis was made.

Results: The mean patient age was 59 years $(\mathrm{SD} \pm 14.9)$. Most of the patients $(61 \%)$ were women, and the most frequent location of the lesions was the buccal mucosa $(90.8 \%)$. White forms of OLP were noted in $66 \%$ of the cases, and $46.2 \%$ of the patients reported symptoms of some kind. The patients diagnosed with diabetes mellitus $(20 \%)$ showed a larger proportion of red lesions $(\mathrm{p}=0.088)$. No statistically significant association was observed between chronic liver disease and the OLP lesion types or symptoms. Two cases of squamous cell carcinoma were identified in two patients previously or simultaneously diagnosed with OLP. A statistically significant correlation was observed between dysplastic changes / malignization of the lesions and smoking habit $(\mathrm{p}=0.019)$. An association to alcohol abuse was also noted, though in this case statistical significance was not reached $(\mathrm{p}=0.085)$.

Conclusions: The clinical features of our study population were similar to those described in other studies. Diabetic patients with OLP were seen to be more susceptible to the development of atrophic-erosive lesions. Smokers and/or patients with alcohol abuse in turn showed a greater tendency to develop dysplastic changes / malignization in the histopathological study of the lesions.
\end{abstract}

Key words: Oral lichen planus, diabetes mellitus, hepatitis, malignization. 


\section{Introduction}

Oral lichen planus (OLP) is a chronic disease affecting the skin, nails, scalp and mucosal membranes. It is observed mainly in middle-aged women, and affects $0.1-4 \%$ of the general population (1). Bagán et al. (2) classify the disorder as white OLP in the presence of reticular or plaque lesions, and as red OLP in the presence of atrophic or erosive lesions, independently of whether or not these coincide with reticular lesions at the periphery or in other locations. The reticular forms are characterized by the presence of whitish streaks known as Wickham striae, typically located on the buccal mucosa. When the epithelium is thin, clinical examination reveals an intense reddish mucosa, due to transparency of the connective tissue vessels. In some areas, this thin epithelium can become fragmented and give rise to the erosive form. Regarding the histology, the most characteristic findings are the presence of a $\mathrm{T}$ lymphocyte and macrophage infiltrate forming a subepithelial band, and hydropic degeneration of the basal layer (2).

Although the precise etiology of OLP is unknown, in most cases a multifactorial process is considered to be involved, with the participation of genetic, psychological and infectious factors. Some of these factors could act as causal agents, while others may trigger the process. At present, OLP is believed to be an autoimmune disorder characterized by an epithelial basal cell lesion that induces an autoimmune response, mainly mediated by the $\mathrm{T}$ lymphocyte population (3).

In 1978, the World Health Organization classified OLP as a precancerous lesion, i.e., since then it has been regarded as a generalized process associated with a significantly increased risk of developing cancer (4). Although a number of studies have analyzed the malignant transformation of OLP, such malignization remains the subject of controversy (5-7).

The present study describes the clinical features of patients diagnosed with oral lichen planus (OLP) and eval- uates the prevalence of its potential malignant transformation in our setting.

\section{Patients and Methods}

A retrospective study was made of 65 patients clinically and histologically diagnosed with OLP (according to the World Health Organization (WHO) criteria of 1978, modified by van der Meij et al. in 2003 (4) in the Service of Oral Surgery (Dental Clinic of the University of Barcelona, Spain) in the period 1990-2005. All the data were collected from the patients' clinical files by a single observer. The following clinical and histological variables were analyzed: demographic variables (age and gender), location, symptoms and clinical presentations of the lesions according to the classification of Bagán et al. (2), systemic disorders associated to OLP (arterial hypertension, diabetes mellitus and chronic liver disease), psychological factors such as anxiety and/or depression (diagnosed by a clinician), coadjuvant local factors (smoking and/or alcohol abuse, oral hygiene scored as good, regular or deficient), mean duration of patient follow-up, dysplastic alterations or malignization, and the treatment applied in each case. A descriptive and bivariate statistical analysis was made (Kolmogorov-Smirnov test, Pearson chi-squared test, fisher exact test and Student t-test) using the Statistical Package for the Social Sciences version 12.0 (SPSS Inc., Chicago, USA) (license of the University of Barcelona, Spain).

\section{Results}

The patient age range was $16-88$ years (mean 59 years; $\mathrm{SD} \pm 14.9) ; 61 \%(\mathrm{n}=40)$ were females and $39 \%(\mathrm{n}=25)$ males. In $95.4 \%$ of the cases $(n=62)$ an incisional biopsy was made, while an excisional biopsy was performed in $4.6 \%(n=3)$. At initial presentation, the white form predominated: $66 \%(n=43)$ versus the red form in $34 \%$ of the cases $(n=22)$. Some patients presented lesions in more than one anatomical location (Fig. 1). Symptoms of

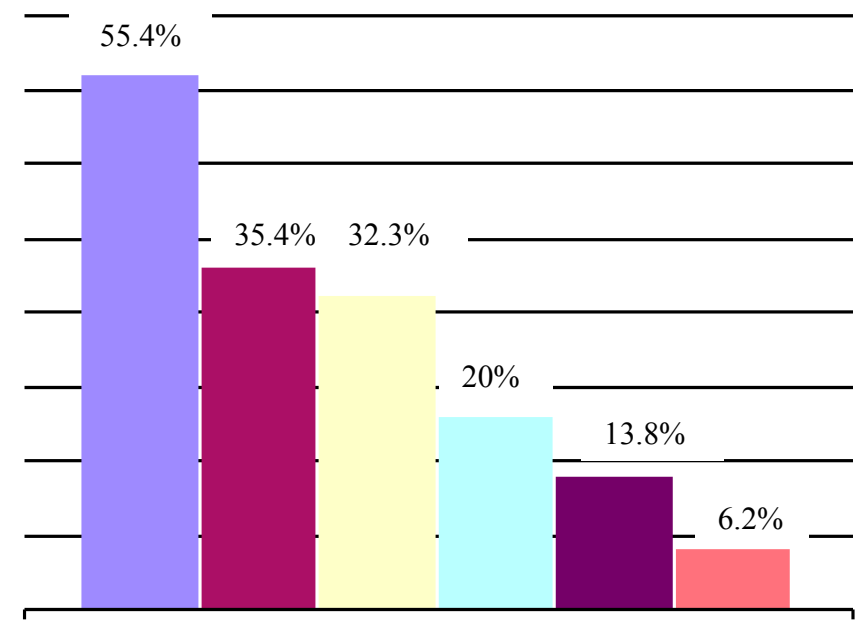

- Bilateral buccal mucosa

- Unilateral buccal mucosa

Tonguc

Gums

$\square$ Palate

Skin involvement

Fig. 1. Anatomical location of the oral lichen planus lesions. 


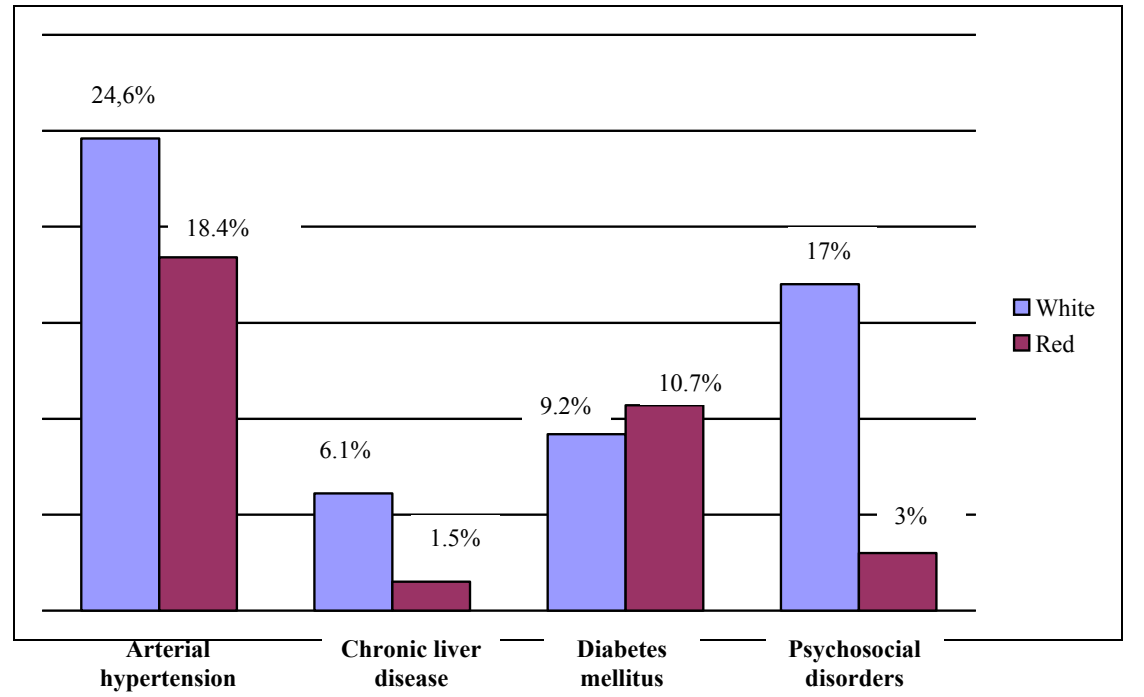

Fig. 2. Relationship between the clinical presentation of oral lichen planus and the existence of systemic diseases.

some kind were reported by $46.2 \%$ of the patients (pain in $26.2 \%$, pruritus in $15.4 \%$, and dry mouth in $4.6 \%$ ). The mean follow-up time was 18.2 months (range 10 days to 212 months). A total of $27.7 \%$ of the study sample consisted of smokers or ex-smokers, and $20 \%$ had present or past antecedents of alcohol abuse.

The patients diagnosed with diabetes mellitus showed a predilection for red lesions $(\mathrm{p}=0.088)$. No statistically significant association was observed between the presence of chronic liver disease and the type of OLP lesions or symptoms (Fig. 2).

Two squamous cell carcinomas were documented (3.1\%) (Tables 1 and 2). In only one of these cases was malignization identified in the same location where OLP had been diagnosed two years previously (patient 1). In the other case, on sampling different areas of the oral cavity for histological study, we detected squamous cell carcinoma coexisting with the OLP lesions (patient 2). We diagnosed one case of moderate dysplasia with lichenoid characteristics that was not included in the sample, since by definition dysplastic alterations are an exclusion criterion for OLP lesions. A statistically significant association was observed between smoking and the existence of dysplastic alterations / malignization $(\mathrm{p}=0.019)$. Lastly, a nonsignificant association was observed between alcohol abuse and these histological alterations $(\mathrm{p}=0.085)$.

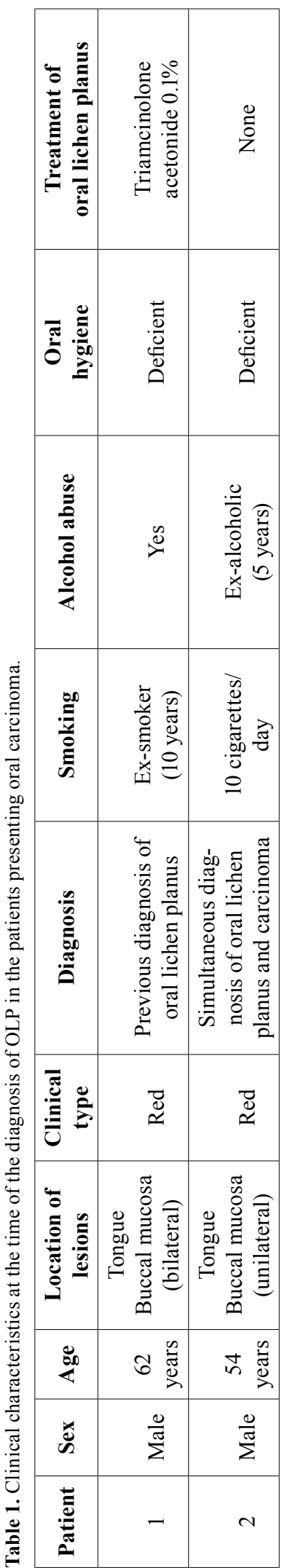


Table 2. Clinical / histological features of the patients with OLP who presented oral carcinoma.

\begin{tabular}{|c|c|c|c|c|c|c|c|c|}
\hline Patient & Age & Location & Symptoms & Histology & $\begin{array}{c}\text { TNM } \\
\text { stage }\end{array}$ & Treatment & $\begin{array}{c}\text { Duration of } \\
\text { follow-up }\end{array}$ & $\begin{array}{c}\text { Complications } \\
\text { and/or } \\
\text { recurrences }\end{array}$ \\
\hline 1 & $\begin{array}{c}64 \\
\text { years }\end{array}$ & Tongue & $\begin{array}{c}\text { Mild pain, } \\
\text { inflammation }\end{array}$ & $\begin{array}{c}\text { Microinfiltrat- } \\
\text { ing squamous } \\
\text { cell carcinoma }\end{array}$ & $\mathrm{T}_{1} \mathrm{~N}_{0} \mathrm{M}_{0}$ & $\begin{array}{c}\text { Surgery, } \\
\text { brachytherapy }\end{array}$ & 68 months & None \\
\hline 2 & $\begin{array}{c}54 \\
\text { years }\end{array}$ & Tongue & Asymptomatic & $\begin{array}{c}\text { In situ } \\
\text { Squamous cell } \\
\text { carcinoma }\end{array}$ & $\mathrm{T}_{\text {is }} \mathrm{N}_{0} \mathrm{M}_{0}$ & Surgery & 84 months & None \\
\hline
\end{tabular}

\section{Discussion}

As has been seen in most studies, OLP preferentially manifests in the fifth and sixth decades of life, and is more common in women $(2,8)$. However, although some authors such as Eisen (8) describe the red presentation as the most frequent clinical form of the disease, we and other authors have recorded more white clinical presentations $(9,10)$. We believe that the occasionally reported greater presence of red lesions is due to the fact that patients with white-form OLP do not tend to visit the dentist for such lesion - since most remain asymptomatic and are diagnosed on occasion of a routine oral exploration. In contrast, patients with red lesions tend to visit the dentist because of pain or itching in the affected zone. In coincidence with Carbone et al. (9), the most commonly affected location was the buccal mucosa, particularly in its posterior third. Such lesions typically manifested bilaterally and symmetrically, and extended in an anterior direction. Our observed incidence of lesions on the tongue (32.3\%) and gums (20\%) was slightly lower than reported by these authors (9).

As has been commented above, the white lesions normally cause no discomfort, and any symptoms that may appear consist of a sensation of mucosal roughness and tautness in the area of the lesions. In contrast, the red lesions can cause important pain, depending mainly on the extent of the lesions, their location and aggressivity. In some cases these forms can be confused with other autoimmune conditions (vesicular-erosive diseases) that have similar clinical characteristics. Another common manifestation in these patients is xerostomia (dry mouth). In our series of 65 patients, $20 \%$ reported nonspecific discomfort (15.4\% itching and $4.6 \%$ dry mouth), and $26.2 \%$ complained of pain of variable intensity. The rest of the patients (53.8\%) showed no symptoms.

OLP tends to develop in individuals subjected to great tension, strong emotions, anxiety or other psychological disorders such as depression. These factors can either trigger onset of the disease or cause existing disease to worsen. The underlying mechanism of action is not clear. In our series it was not possible to adequately evaluate these factors, due to the limitations imposed by the study design. In coincidence with the observations of Bagán et al. (11), we found patients with diabetes mellitus to have a greater tendency to develop red lesions.

The literature has extensively addressed the relationship between OLP and chronic liver disease. A number of authors (12) support the existence of such a relationship, while others such as Micó et al. (13) have observed no association between OLP and hepatitis B and/or C infection. Regarding the aggressivity of the OLP lesions in patients with chronic liver disease, some studies (14) have shown that the greater the degree of liver disease (as determined by blood transaminase elevation), the greater the aggressivity of the OLP lesions. In our series no significant association was observed between chronic liver disease and the aggressivity of the lesions. A possible reason for this apparent lack of association could be the limited size of our sample. On the other hand, it must be mentioned that our study design was not the best for assessing associations between OLP and the different associated systemic disorders, since no control group was established for comparing the incidence of such diseases.

A number of studies suggest that OLP patients are at an increased risk of developing cancer, though few have been able to demonstrate statistically significant differences with respect to the general population $(15,16)$. An incorrect diagnosis (epithelial dysplasia, lichenoid lesions or other disorders), the non-identification of carcinogenic factors, and the fact that in some cases the location of carcinoma does not correspond to that of the initial biopsy, are the main reasons for questioning the validity of most of these studies.

Of the two carcinomas detected in our series, only patient 1 had a previous clinical and histopathological diagnosis of OLP in the same area where the cancer was later identified. Therefore, after excluding patient 2 (since in this case the diagnosis of OLP coincided with 
that of squamous cell carcinoma) and patient 3 (where the diagnosis was moderate dysplasia - not carcinoma), the OLP malignization rate in our series was $1.5 \%$. The malignization rate found in the literature ranges from $0-12.5 \%$, and depends on the study group involved and on the duration of follow-up (17). It has been suggested that a high incidence of oral carcinoma in OLP patients could be due to diagnostic error in differentiating between OLP as such and epithelial dysplasia with lichenoid features (18). The distinction between these two conditions can be very difficult, since the clinical and histological features are often very similar. In our series we identified a case of epithelial dysplasia with lichenoid characteristics located on the lateral margin of the tongue.

Although a biopsy is essential for the diagnostic conformation of OLP, an evaluation based only on the histopathological findings may preclude a correct diagnosis. For example, while contact lichenoid reactions histologically may show increased inflammatory infiltration with eosinophils and plasma cells, and a greater presence of Civatte bodies than in OLP (19), in some cases the histological picture is indistinguishable from that of OLP (20). Van der Meij et al. $(6,7)$ observed a strong but statistically nonsignificant association between squamous cell carcinoma and lichenoid lesions, though no relationship between cancer and OLP was noted. Therefore, a precise clinical as well as histopathological diagnosis of these lesions is required, since error in differentiating between the two disorders could wrongly suggest an increased malignization rate on the part of OLP.

Although Gandolfo et al. (16) are of the opinion that malignant degeneration of OLP is independent of the type of lesions involved, the fact is that malignization has been mainly reported in relation to intensely recurrent and aggressive red lesions $(8,15)$. However, the literature also contains less frequent series in which malignization has been reported mainly in relation to plaquetype white lesions, in combination or not with a reticular pattern (21). The cause of a possible increase in oral cancer risk in patients diagnosed with OLP is not clear, though the oral mucosa affected by OLP may be more sensitive to exogenous factors such as smoking, alcohol abuse or colonization by Candida albicans (1). However, some authors are of the opinion that the intense chronic inflammation found particularly in the red lesions plays an important role in possible carcinogenesis - causing genetic damage and inducing tissue proliferation (22). Murti et al. (23) have reported that the red forms appear to imply a greater disposition to develop squamous cell carcinoma when exposed to the carcinogenic action of smoking. On the other hand, van der Meij et al. (6) have recorded no relationship between smoking and alcohol abuse, and the malignization of OLP. In our series, patient 1 had been exposed to known carcinogenic factors for a long period of time, and this may have favored the development of carcinoma from a red lesion (Table 1). Some published series have found that OLP patients who develop oral cancer present clinical features that are different from those of patients with oral carcinoma. Such patients are predominantly women, relatively young, and with carcinoma preferentially located in the buccal mucosa, which is regarded as a low risk zone for the development of cancer $(6,16)$. Coombes et al. (24) described a squamous cell carcinoma in the center of the back of the tongue - a zone considered to involve a very low risk (less than $1 \%$ of all tongue cancers) -10 years after diagnosing OLP in the same area. All these observations could indicate that the malignization of OLP is part of the natural course of the disease, i.e., OLP would constitute a precancerous lesion. However, these data do not coincide with our own findings, since patients 1 and 2 presented some clinical features that are characteristic of patients with upper aerodigestive cancers (male sex, age 45-65 years, septic mouth, a history of smoking and alcohol abuse, etc.). In addition, in both cases the carcinoma was located on the tongue, which is regarded as a high risk zone for the development of cancer.

Thus, we have not been able to determine whether malignization was due to the natural biological behavior of OLP or to an increased susceptibility of the lesion to the action of carcinogenic factors (since both patients were exposed to smoking and alcohol), or whether the simultaneous presence of both disorders was a mere coincidence. Nevertheless, we consider it advisable to establish periodic controls of patients with OLP, since the early treatment of cancer lesions offers satisfactory results. As commented by González-Moles et al. (25), in order to establish the intrinsic capacity of OLP to undergo malignization, it is necessary to conduct new prospective studies with OLP patients and a control group of subjects without OLP. Moreover, both groups must include smokers and non-smokers. In this context, given the low incidence of oral cancer in the general population, and specifically in patients with OLP, a very large patient sample would be needed, with a follow-up period of at least 5 years (18).

\section{Conclusions}

The clinical features of our study population (gender, age and location of the lesions) were similar to those described in other studies. The results suggest that diabetic patients with OLP are more susceptible to the development of red OLP lesions. Smokers and/or patients with alcohol abuse in turn showed a greater tendency to develop dysplastic changes / malignization in the histopathological study of the lesions. Despite the uncertainty over the premalignant nature of OLP, it seems reasonable to monitor these patients regularly and for life. 


\section{References}

1. Sugerman PB, Savage NW, Walsh LJ, Zhao ZZ, Zhou XJ, Khan A, et al. The pathogenesis of oral lichen planus. Crit Rev Oral Biol Med. 2002;13:350-65.

2. Bagán-Sebastián JV, Milián-Masanet MA, Peñarrocha-Diago M, Jiménez Y. A clinical study of 205 patients with oral lichen planus. J Oral Maxillofac Surg. 1992;50:116-8.

3. Cortés-Ramírez DA, Gainza-Cirauqui ML, Echebarria-Goikouria MA, Aguirre-Urízar JM. Enfermedad liquenoide oral como condición premaligna: controversias e incógnitas. Med Oral Patol Oral Cir Bucal.2009;14:145-9.

4. Van der Meij EH, Van der Waal I. Lack of clinicopathologic correlation in the diagnosis of oral lichen planus based on the presently available diagnostic criteria and suggestions for modifications. J Oral Pathol Med. 2003;32:507-12.

5. Bermejo-Fenoll A, Sanchez-Siles M, López-Jornet P, CamachoAlonso F, Salazar-Sanchez N. Premalignant nature of oral lichen planus. A retrospective study of 550 oral lichen planus patients from south-eastern Spain. Oral Oncol. 2009;45:e54-6.

6. Van der Meij EH, Schepman KP, Van der Waal I. The possible premalignant character of oral lichen planus and oral lichenoid lesions: a prospective study. Oral Surg Oral Med Oral Pathol Oral Radiol Endod. 2003;96:164-71.

7. Van der Meij EH, Mast H, Van der Waal I. The possible premalignant character of oral lichen planus and oral lichenoid lesions: a prospective five-year follow-up study of 192 patients. Oral Oncol. 2007;43:742-8

8. Eisen D. The clinical features, malignant potential, and systemic associations of oral lichen planus: a study of 723 patients. J Am Acad Dermatol. 2002;46:207-14.

9. Carbone M, Arduino PG, Carrozzo M, Gandolfo S, Argiolas MR, Bertolusso G, et al. Course of oral lichen planus: a retrospective study of 808 northern Italian patients. Oral Dis. 2009;15:235-43.

10. Pakfetrat A, Javadzadeh-Bolouri A, Basir-Shabestari S, Falaki F. Oral Lichen Planus: a retrospective study of 420 Iranian patients. Med Oral Patol Oral Cir Bucal. 2009;14:E315-8.

11. Bagan JV, Donat JS, Penarrocha M, Milian MA, Sanchis JM. Oral lichen planus and diabetes mellitus. A clinico-pathological study. Bull Group Int Rech Sci Stomatol Odontol. 1993;36:3-6.

12. Carrozzo M, Gandolfo S, Carbone M, Colombatto P, Broccoletti $\mathrm{R}$, Garzino-Demo $\mathrm{P}$, et al. Hepatitis $\mathrm{C}$ virus infection in Italian patients with oral lichen planus: a prospective case-control study. J Oral Pathol Med. 1996;25:527-33.

13. Míco-Llorens JM, Delgado-Molina E, Baliellas-Comellas C, Berini-Aytés L, Gay-Escoda C. Association between B and/or C chronic viral hepatitis and oral lichen planus. Med Oral. 2004;9:18390.

14. Ali AA, Suresh CS. Oral lichen planus in relation to transaminase levels and hepatitis C virus. J Oral Pathol Med. 2007;36:604-8.

15. Rödström PO, Jontell M, Mattsson U, Holmberg E. Cancer and oral lichen planus in a Swedish population. Oral Oncol. 2004;40:131-8.

16. Gandolfo S, Richiardi L, Carrozzo M, Broccoletti R, Carbone M, Pagano M, et al. Risk of oral squamous cell carcinoma in 402 patients with oral lichen planus: a follow-up study in an Italian population. Oral Oncol. 2004;40:77-83.

17. Barnard NA, Scully C, Eveson JW, Cunningham S, Porter SR. Oral cancer development in patients with oral lichen planus. J Oral Pathol Med. 1993;22:421-4.

18. Lodi G, Scully C, Carrozzo M, Griffiths M, Sugerman PB, Thongprasom K. Current controversies in oral lichen planus: report of an international consensus meeting. Part 2. Clinical management and malignant transformation. Oral Surg Oral Med Oral Pathol Oral Radiol Endod. 2005;100:164-78.

19. Scully C, Carrozzo M. Oral mucosal disease: Lichen planus. Br J Oral Maxillofac Surg. 2008;46:15-21.

20. Van der Waal I. Oral lichen planus and oral lichenoid lesions; a critical appraisal with emphasis on the diagnostic aspects. Med Oral Patol Oral Cir Bucal. 2009;14:E310-4.
21. Lanfranchi H, Aguas S, Sano S. Transformación maligna del liquen plano bucal atípico: análisis de 32 casos. Med Oral.2003;8:2-9.

22. Schottenfeld D, Beebe-Dimmer J. Chronic inflammation: a common and important factor in the pathogenesis of neoplasia. CA Cancer J Clin. 2006;56:69-83.

23. Murti PR, Daftary DK, Bhonsle RB, Gupta PC, Mehta FS, Pindborg JJ. Malignant potential of oral lichen planus: observations in 722 patients from India. J Oral Pathol. 1986;15:71-7.

24. Coombes D, Cascarini L, Booth PW. Carcinoma of the midline dorsum of the tongue. Br J Oral Maxillofac Surg. 2008;46:485-6.

25. Gonzalez-Moles MA, Scully C, Gil-Montoya JA. Oral lichen planus: controversies surrounding malignant transformation. Oral Dis. 2008;14:229-43.

\section{Acknowledgements}

This study has been carried out by the research group in "Dental and Maxillofacial Pathology and Treatment" of the Institut d'Investigació Biomèdica de Bellvitge (IDIBELL), with financial support from the oral surgery teaching-healthcare agreement among the University of Barcelona, the Consorci Sanitari Integral and the Servei Català de la Salut of the Generalitat de Catalunya. 